\title{
HISTOMORPHOMETRIC CHANGES OF GONADS IN MALE GUINEA PIGS AFTER THYMECTOMY
}

\section{P.Murali ${ }^{1}$, J. Radhika $* 2$,}

${ }^{{ }^{1}}$ Research scholar, Department of Anatomy, SRM Medical College Hospital and Research Centre, Kattankulathur,Tamilnadu,India.

${ }^{2}$ Professor, SRM Medical College Hospital and Research Centre, Kattankulathur, Tamilnadu, India.

\section{ABSTRACT}

Introduction: The presence of the thymus gland during early life is essential for the normal development of immune system and as well as proper maturation of the hypothalamic - pituitary-gonadal axis. This study was to investigate the influence of thymus gland on male reproductive function.

Aim: The aim of this study to investigate the effect of thymectomy on Morphometric changes of gonads in neonatal, prepubertal and pubertal thymectamized male guinea pigs.

Material and Methods: In this study, a total of thirty male guinea pigs, thymectamized (n-6) and sham-operated $(n-4)$ were studied in each group. The comparison of diameter of seminiferous tubules, luminal diameter and epithelial thickness in the thymectamized and sham operated male guinea pigs.

Results: No Significant changes in the morphometry of seminiferous tubules of testis in thymectamized male guinea pigs compared to the sham-operated guinea pigs in all age groups. These results suggest that thymectomy had no detrimental effects on reproductive system in males at any intervals.

KEY WORDS: Thymectomy, Seminiferous diameter, Luminal diameter and Epithelial thickness.

Corresponding Author: Dr. J. Radhika, Professor, SRM Medical College Hospital and Research Centre, Kattankulathur, Tamilnadu, India. E-Mail: pmurali.pt@gmail.com

Access this Article online

Quick Response code

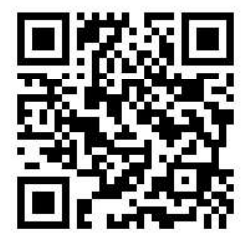

DOI: $10.16965 /$ ijar.2019.338
Journal Information

International Journal of Anatomy and Research

ICV for 2016 ISSN (E) 2321-4287 | ISSN (P) 2321-8967

90.30

https://www.ijmhr.org/ijar.htm

DOI-Prefix: https://dx.doi.org/10.16965/ijar

\section{Article Information}

Received: 06 Nov 2019

Peer Review: 06 Nov 2019

Revised: None
Accepted: 19 Nov 2019

Published (O): 05 Dec 2019

Published (P): 05 Dec 2019

\section{INTRODUCTION}

The presence of the thymus gland during early stage of life is essential for the normal development of immunological system and proper maturation of the hypothalamic- pituitarygonadal axis. The primary function of hypothalamic-pituitary-gonadal axis is essential for maintaining proper reproductive function. A thymic epithelial cell secretes several bioactive molecules such as thymulin, which promotes, activates and differentiation of T-cells and stimulates gonadotropins [1-3]. There has been an increasing interest in the relationship between the thymus and reproductive development and function within the last 50 years (Nishizuka \& Sakakura, 1970, 1971; Rebar et al., 1981; Farookhi et al., 1988; Andersson, 1992; Bloom et al., 1992; Jin et al., 1995; Su et al., 2013; Sharma et al., 2014) [4-12]. Calzolari (1898) [13] have reported relationship between thymus and gonadal function; the experiment were made upon rabbits and guinea pigs and the results that conformed thymic enlargement occurs after gonadectomy in both sex.

Dougherty (1952) [14] observed that the androgen and estrogens induce the distraction of the thymus when administered to thymic bearing animals. The neuroendocrine influence on the 
thymus seems to be extremely complex with apparent presence of complete intra thymic biological circuit involving the synthesis of pituitary hormones and expression of their respective receptors by thymic epithelial cells [3]. Previous investigations of neonatally thymectomized rodents (Lintern-Moore, 1977; Hattori and Brandon, 1979; Deschauxet al., 1979) [15-17] and these have concentrated basically on the impacts of thymectomy on gonadal development or Function. Taguchi et al. (1980) have reported that in thymectamized mice at three days resulted in an autoimmune state [18]. In males, many of studies have reported the hormone such as thymulin secreted by thymic cells stimulates the proliferation of testicular gonocytes [19] and various endocrinological studies also reported the hormones secreted by the thymic epithelial cells and the thymic lymphocytes modulated the testicular function, such as thymulin hormone secreted by thymic epithelial cells, stimulate the proliferation of different stages of testicular gonocytes [15]. A congenital athymic male mouse shows significant reduction of follicular stimulating hormone luteinizing hormone. Histologically, the reduced number of leydig cells and reduced concentration level of testosterone in adult rat [20]. But the Patson (1911) found that thymectomy does not result in testicular hypertrophy and does not affect the growth of the immature animal [21].

The above interactions occur at different stages of life such as embryonic and neonatal development to maintain the normal homeostatic balance. The neuroendocrine control of the thymus appears to be extremely complex with apparent presence of complete intra thymic biological circuitry involving the production of pituitary hormones, as well as the expression of their respective receptors by thymic cells [7].

All these findings imply a functional correlation between the thymic hormones and gonadal hormones but the Morphometric and histoarchitectural changes of the gonads in both sexes after thymectomy have not been sufficiently studied. Hence the present study describes the histo-morphometric changes of male gonads after thymectomy in neonatal, pre pubertal and pubertal guinea pigs.

\section{MATERIALS AND METHODS}

This present study was conducted in the central animal house and department of anatomy at SRM Medical College and Research Centre, Kattankulathur, Tamilnadu, India.

Experimental Animals: Experimental studies were performed on the first week (Neonatal Average weight 90 to $100 \mathrm{gm}$ ), fifth week (Pre-Pubertal Average weight 200 to $250 \mathrm{gm}$ ) and seventh week (pubertal Average weight 280 to $300 \mathrm{gm}$ ) old male guinea pigs. In this study, a total of thirty male guinea pigs were studied. The animals were purchased from the Institute of Experimental Animals, Bangalore Karnataka. The animals were housed in the SRM Central Animal House and Kept in pathogen free stainless steel pan with Cone cap bedding Material. Auto claved Pots and disposable cardboard boxes were used for hiding, which might also prevent aggressive behaviour in animals, four in each cage. Double - distilled water, Pallets and fruits were given at regular intervals and maintained at $60-65 \%$ of humidity. The room was maintained with adequate lighting consisting of dark and light cycle for 12 $\mathrm{h} /$ day and the temperature was maintained at $25 \dot{c} \pm 2 \dot{c}$ " C. The present study was approved by the Institutional Animal ethical committee of SRM IST Chennai, in accordance with the CPCSEA guidelines, bearing the number 16111/835reS-04/IAEC2016.

Experimental design: In this study total of 30 male guinea pigs were used. Animals were divided into two main groups. The group I (n-4) animals underwent full operating procedure but without ablation of thymus gland which was considered as Sham operated group. Group II (n-6) consists of the guinea pigs with surgically removed thymus which was the thymectamized group.

Surgical Procedure: The animals were operated upon under inhalation anesthesia; Thymectomy of the guinea pigs was performed according to the procedure described by Adams DB, 1977 [22]. At end of the procedure suture area of the skin cleaned with saline-moistened gauze. No special treatment will be required as it surgical wound.

Euthanasia and tissues sample collection: Both 
thymectamized and sham operated guinea pigs in each group were sacrificed after 60 days. The animals were euthanized by using $\mathrm{CO} 2$ for euthanasia. Testis and accessory reproductive tissues were collected in Bouins fluid and stained with $\mathrm{H}$ \& $\mathrm{E}$. The assessment of the seminiferous tubules diameter, luminal diameter and epithelial thickness of seminiferous tubules were performed according to the procedure described by Temidayo $S$ et al., 2018 [23]. The diameter of seminiferous tubules, luminal diameter and height of the seminiferous tubule epithelium was measured at $\times 200$ and $\times 400$ magnifications using image analyzer Leica (DMLB) and Leica Qwin software.

Statistical analysis: Descriptive statistics was calculated for the tubular dimension and the results were expressed as mean \pm SEM. One-way ANOVA was performed to compare the parameter in different groups of male guinea pigs. When the test indicated a significant difference (pÂ0.05), the Turkey post hoc test was performed. The analysis was performed using Graph Pad Prism 6 soft ware (CA, USA).

\section{RESULTS}

Morphometric analysis of seminiferous diameter of the testis was analyzed at $60^{\text {th }}$ day after the thymectomy in neonatal, prepubertal and pubertal male guinea pigs.

Diameter of seminiferous tubules of testis: The mean (SEM) diameter of the seminiferous tubule in neonatal, prepubertal and pubertal Sham-operated guinea pigs was $958 \pm 24.4$, $1086 \pm 38.5$ and $1199 \pm 3.31 \mu \mathrm{m}$, respectively (Table 1) The mean (SEM) diameter of the seminiferous tubule in neonatal, prepubertal and pubertal thymectamized guinea pigs was - $880 \pm 7.30,1084 \pm 13.7$ and $1136 \pm 3.56$ respectively (Table 1 ). However, the Morphometric analysis of seminiferous diameter of the testis was analyzed by one-way ANOVA test between the sham-operated and thymectamized group revealed that there was no statistically significant difference between sham-operated and experimental animals.

Luminal diameter of seminiferous tubules of testis: The mean (SEM) diameter of the seminiferous tubule in neonatal, prepubertal and pubertal Sham-operated guinea pigs was
$393.7 \pm 04.25,464.5 \pm 08.5$ and $640.7 \pm 10.7 \mu \mathrm{m}$, respectively (Table 1 ) The mean (SEM) diameter of the seminiferous tubule in neonatal, prepubertal and pubertal thymectamized guinea pigs was $389 \pm 03.69,456 \pm 03.50$ and $630 \pm 08.7 \mu \mathrm{m}$ respectively (Table 1 ). However, the seminiferous luminal diameter of the seminiferous tubules between the sham-operated and thymectamized group showed there was no statistically significant difference between sham-operated and experimental animals in all age groups.

Epithelial thickness of seminiferous tubules: The mean (SEM) Epithelial thickness of the seminiferous tubule in neonatal, prepubertal and pubertal Sham-operated guinea pigs was $230 \pm 07.91,261 \pm 03.41$ and $280.5 \pm 05.01 \mu \mathrm{m}$, respectively (Table 1 ) The mean (SEM) diameter of the seminiferous tubule in neonatal, prepubertal and pubertal thymectamized guinea pigs was $222 \pm 11.03,259 \pm 01.83$ and $274 \pm 04.30 \mu \mathrm{m}$ respectively (Table 1). However, the thymectamized male guinea pigs showed Epithelial thickness of the seminiferous tubules there was no statistically significant when compared to the sham-operated in all age groups.

Fig. 1: Comparison of Diameter of seminiferous tubules between the thymectamized and sham-operated group's male guinea pigs in different age groups.

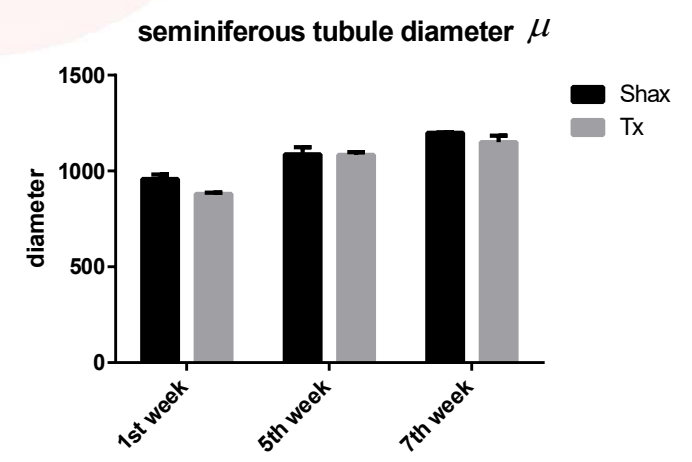

Fig. 2: Comparison of Luminal diameter of seminiferous tubules between the thymectamized and sham-operated group's male guinea pigs in different age groups.

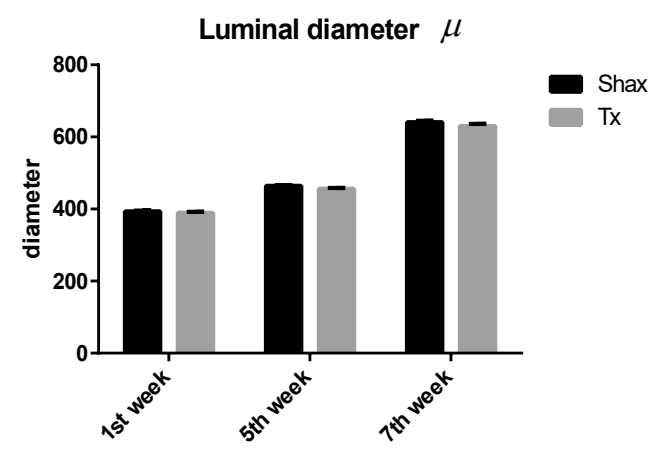


Table 1: Comparison of Morphometric analysis of seminiferous tubules of the testis between the thymectamized and sham-operated animals in different age groups. Values expressed as Mean with SEM.*significant $\mathrm{P}<0.05$.

\begin{tabular}{|c|c|c|c|c|c|c|}
\hline \multirow{2}{*}{ Group } & \multicolumn{2}{|c|}{ Seminiferous diameter $\mu \mathrm{m}$} & \multicolumn{2}{c|}{ Luminal diameter $\mu \mathrm{m}$} & \multicolumn{2}{c|}{$\begin{array}{c}\text { Seminiferous epithelial } \\
\text { diameter } \mu \mathrm{m}\end{array}$} \\
\cline { 2 - 7 } & Shax $\mathrm{n}-4$ & Tx $\mathrm{n}-6$ & Shax $\mathrm{n}-4$ & Tx $\mathrm{n}-6$ & Shax $\mathrm{n}-4$ & Tx $\mathrm{n}-6$ \\
\hline $\mathbf{1}^{\text {st }}$ week & $958 \pm 24.4$ & $880 \pm 07.30$ & $393.7 \pm 04.25$ & $389 \pm 03.69$ & $230 \pm 07.91$ & $222 \pm 11.03$ \\
\hline $5^{\text {th }}$ week & $1086 \pm 38.5$ & $1084 \pm 13.7$ & $464.5 \pm 08.50$ & $456 \pm 03.50$ & $261 \pm 03.41$ & $259 \pm 01.83$ \\
\hline $7^{\text {th }}$ week & $1199 \pm 3.31$ & $1136 \pm 3.56$ & $640.7 \pm 10.7$ & $630 \pm 08.7$ & $280.5 \pm 05.01$ & $274 \pm 04.30$ \\
\hline
\end{tabular}

Fig. 3: Comparison of Epithelial diameter of seminiferous tubules between the thymectamized and sham-operated group's male guinea pigs in different age groups.

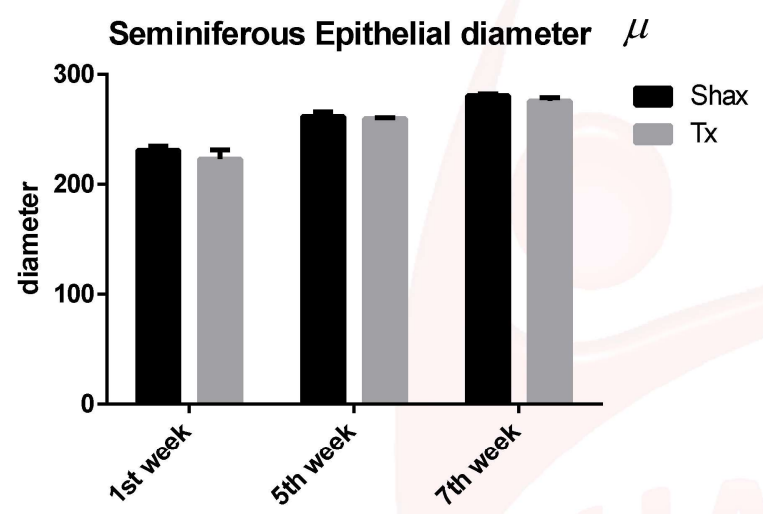

Fig. 4: Showing Morphometry of seminiferous tubule in Micrograph. Seminiferous tubule diameter (- and -) continues line and scatter line (black color).Epithelial height (red line).Luminal diameter (continues line black color).

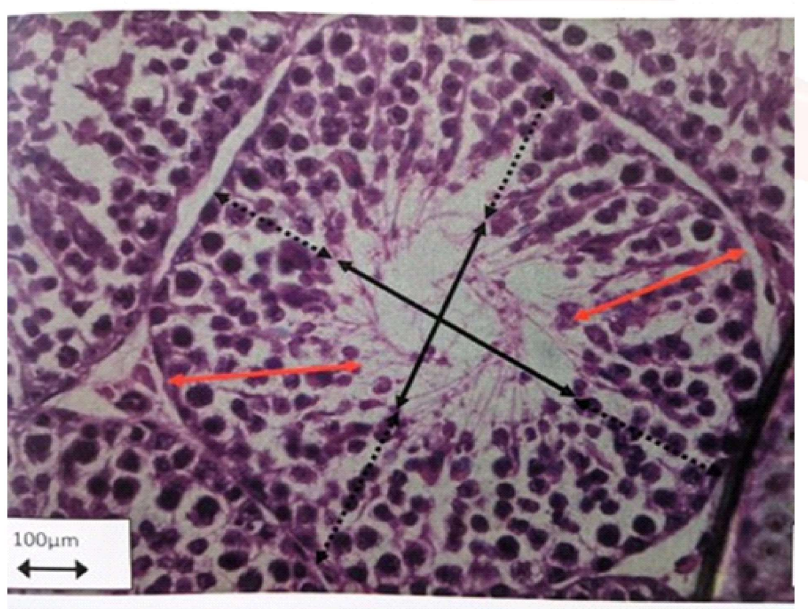

\section{DISCUSSION}

During neonatal period to grown-up period there has been a dynamic increase in the testicular volume as well as in the length and width of the seminiferous tubules, without change in the Sertoli cell number per testis. This number of cells might be considered as a constant, for grown-up testicles as well as for postnatal developing testicles [24]. The parameters investigated in this study were Seminiferous Diameter, Seminiferous Epithelial Height, and
Luminal Diameter of the seminiferous tubules in thymectamized guinea pigs compared to the sham-operated guinea pigs. These results showed there was no significant difference in Histo-Morphometric changes between the thymectamized and sham-operated guinea pigs. Therefore thymectomy effects on the different age groups of the male guinea pigs examinated in the present study were free from specific failure of spermatogenesis.

Plagge et al., 1941 [25] have reported thymectamized pubertal male rat had statistically no significant effect on testicular growth, gonadotropin secretion and spermatogenesis and there were no significant changes in onset of spermatogenesis between thymectamized and control animals. However, negligible amount of interstitial spaces were noted within the epithelial layer of seminiferous tubule in neonatal thymectamized male animals. Yasuaki Nishizuka, Teruyo Sakakura et al., 1969 [26] have reported that no positive evidence that sex-linked developmental failure of the gonad is essentially related to depressed immunologic faculty after thymectomy at 3 days of age and thymectamized pubertal male rat had statistically no significant effect on testicular growth, spermatogenesis and gonadotropin secretion and there were no significant changes in the onset of spermatogenesis between thymectamized and control animals. Reber et al1982 [27] have reported congenital athymic mice showed normal morphology of spermatogenesis at pubertal age when compared to the control animals and Vos et al 1980 also observed the absence of morphological alteration in spermatogenesis of athymic nude mice[28]. Above findings were not consistent with our present findings.

In contrast, Hattori and Brandon (1979) [16] have reported decline in LH in the pituitary and atrophic testis with no noticeable changes in 
leydig cells in testis of the thymectamized male mice, when compared with the control group. Bloom et al. (1992) reported that thymectamized females exhibited decreased lordosis in response to estrogen, while thymectamized males showed differences in the mount latency or post-ejaculatory interval with no significant differences in luteinizing hormone (LH) or testosterone (T) levels [9]. Neonatal thymectomy had detrimental effect on reproductive system may be directly or indirectly in males undergoing immunosuppressant at adulthood Mohammad mehdi Ommati et al., 2018 [29]. In addition Prolactin in the male rat has been suggested to play a role in maintenance of LH-responsiveness of the testis (Bartke and Dalteiro, 1976) [30]. Clearly, the decline in both $\mathrm{LH}$ and Prolactin in the pituitaries of the thymectamized male may be a harbinger of the testicular atrophy that Hattori and Brandon (1979) have reported. Shire and Pantelouris et al 1974 [31] have reported congenital athymic mice showed early stage of spermatogenesis appeared to be normal, but their spermiogenesis was disturbed which resulted in few or elongated spermatids and spermatozoa in many seminiferous tubules of the testis in nude mice. The previous studies have explained that effect of surgical removal of the thymus during neonatal period on testicular changes. Neonatal thymectamized rat injected with estrogen induced disturbed spermatogenesis with an absence of spermatids. This experiment data's showed neonatal thymectamized had aspermatogenic seminiferous tubules when compared to the sham operated animals. These results indicate that the spermatogenic state in thymectamized rats is more sensitive to the toxic effect of the steroid than is that in thymus bearing animals [32-35].

There are studies to have reported that the spermatids maturation disturbance due to developing of waste disease [35-37].

Our study results conclude that thymectomy had no detrimental effects on reproductive system in males at any intervals. Further studies are needed to determine whether thymectomy of male affects reproduction directly or indirectly through the hypothalamic-hypophysealgonadal axis.

\section{ACKNOWLEDGEMENTS}

I am indebted to my colleague, Dr. S. Pratheepa Shivashangari, Associate Professor, Department of Anatomy, SRM Medical College Hospital and Research Centre, Kattankulathur, Tamilnadu, India.

\section{Conflicts of Interests: None}

\section{REFERENCES}

[1]. Safieh B, Kendall MD, Norman JC, Metreau E, Dardenne M, Bach J-F \& Pleau JM A new radioimmunoassay for the thymic peptide thymulin and its application for measuring thymulinin blood samples. Journal of Immunological Methods 1990; 127: 255-262.

[2]. Hinojosa L, Chavira R, Dominguez R \& Rosa P Effect of thymulin on spontaneous puberty and Gonadotrophins - induced ovulation in prepubertal normal and hypothymic Mice. Journal of Endocrinology 1999; 163: 255-260.

[3]. Celok Lek, Interaction involving the thymus and the hypothalamus - pituitary axis, immunomodulation by hormones. Srp Arh 2004;132:187-93.

[4]. Nishizuka, Y \& Sakakura, T. Thymus and reproduction: sex linked dysgenesia of the gonad after neonatal thymectomy in mice. Obstet Gynecol Surv 1970;25: 353- 355.

[5]. Nishizuka, Y \& Sakakura, T. Ovarian dysgenesis induced by neonatal thymectomy in the mouse. Endocrinology 1971;89:886- 893.

[6]. Rebar, RW, Morandini, I, Erickson, GF \& Petze, JE The hormonal basis of reproductive defects in athymic mice: diminished gonadotropin concentrations in prepubertal females. Endocrinology 1981;108:120126.

[7]. Farookhi, R, Wesolowski, E, Trasler, J \& Robaire, B. Modulation by neonatal thymectomy of the reproductive axis in male and female rats during development. Biol Reprod 1988;38:91-99.

[8]. Andersson, M. Relationships between GnRH induced testosterone maxima, sperm motility and fertility in Ayrshire bulls. Anim Reprod Sci 1992;27;107111.

[9]. Bloom, DF, Bloch, GJ \& Gorski, RA. Effects of thymectomy on reproductive function and behavior. Physiol Behav 1992;52:291- 298.

[10]. Jin, Z, Yong shang, Z, Pomer, S, Staehler, G \& Da hong, $R$. The influence of thymectomy on germ cells of the testis in mice. J Tongji Med Univ 1995;15:112- 116.

[11]. Su, S, Fang, F, Liu, Y, Li, Y, Ren, C, Zhang, Y \& Zhang, X. The compensatory expression of reproductive hormone receptors in the thymus of the male rat following active immunization against $\mathrm{GnRH}$. Gen Comp Endocrinol 2013;185: 57- 66.

[12]. Sharma, R, Kantwa, SM, Jaitawat, A, Rani, D \& Jain, $N$. Relationship between testis and thymus during postnatal development in Swiss mice. Univ J Environ Res Tech 2014;4:208- 214. 
[13]. Calzolari. A. Recherches experimentales sur un rapport probable entre la function du thymus et cells des testicules, Arch.ital.Biol. Torino. 1898;30:71-77.

[14]. Dougherty SM, Mazhawidza W, Bohn AR, Robinson KA, Mattingly KA, Blankenship KA, Huff MO, McGregor WG, Klinge CM Gender difference in the activity but not expression of estrogen receptors alpha and beta in human lung adenocarcinoma cells. Endocr Relat Cancer. 2006;13(1):113-34.

[15]. Lintern-Moore. Effect of athymia on the initiation of follicular growth in the rat ovary. Biol Reprod 1977;17:155-61.

[16]. Hattori M,Brandon MR,Thymus and the endocrine systemOvarian dygenesis in neonatally thymectomized rats.J Endocrinol. 1979;83(1) : 101-11.

[17]. Deschaux, P, Massengo, B \& Fontanges, R. Endocrine interaction of the thymus with the hypohysis, adrenals and testes: effects of two thymic extracts. 1979; Thymus 1: 95- 108.

[18]. Michael SD, Taguchi O, Nishizuka Y. Effects of neonatal thymectomy on ovarian development and plasma $\mathrm{LH}, \mathrm{FSH}, \mathrm{GH}$ and PRL in the mouse. Biol. Reprod. 1980;22:343-350.

[19]. Kincl, F.A., Folch PI, A., Maqueo, M., Lasso, L.H., Dorfman, and P.J. Inhibition of sexual development in male and female rats treated with various steroids at the age of five days, Acta endocr. 1965;49: 193-206.

[20]. Robert W Rebar, I C Morandini,J E Petze,G F Erickson. Hormonal basis of reproductive defects in athymic mice: Reduced gonadotropins and testosterone in males. Biology of Reproduction 1983:27(5):126776.

[21]. Patson D.N. The Thymus and Sexual organs. Their Relationship to the growth of the animal. J. Physiol. 1911;42: 267.

[22]. Adams DB.The effect of thymectomy in guinea pigs on the lymphocyte content of central lymph.Aust J ExpBiol Med Sci. 1977;55(1): 49-57.

[23]. Temidayo S O, Stefan S d. Diabetes mellitus and male infertility. Asian Pac J Reprod 2018;7:6-14.

[24].CHEMES,H.E.,DYM,M.,FAWCETr,D.W.,JAVADPOUR, N.\&SHERINS,R.Patho-physiological observations of Sertolicellsinpatients With germinal aplasia or severe germ cell depletion.Ultra-structural findings and hormone levels.Andrologia 1977;17:108-123.

[25]. Plagge, J.C. (1941) Thymus gland in relation to sex hormones and reproductive procecesses in albino rats J.morphol.1941;68:519.
[26]. Yasuaki Nishizuka, Teruyo Sakakura.Thymus and Reproduction: Sex-Linked Dysgenesia of the Gonad after Neonatal Thymectomy in Mice.Science. 1969;166 (3906): 753-755.

[27]. Robert W. Rebar I. C. Morandini John E. Petze Gregory F. Erickson. Hormonal Basis of Reproductive Defects in Athymic Mice: Reduced Gonadotropins and Testosterone in Males. Biology of Reproduction, 1982;27(5) : 1267-1276.

[28]. Vos JO. Berkvens JM. Kruijt BC. The athymic nude rat I. Morphology of lymphoid and endocrine organs. Clipi Immuno and Imniunopathol 1980;15:213-228.

[29]. Ommati MM, Heidari R, Zamiri MJ, Shojaee S, Akhlaghi A, Sabouri S. Association of open field behavior with blood and semen characteristics in roosters: an alternative animal model. Rev Int Androl.2018;16(2):50-58.

[30]. Bartke A, Dalteiro. Effects of prolactin on the sensitivity of the testis to LH. Biol Reprod 1976;15:90-93

[31]. Shire, J.G.M. \& Pantelouris, E.M. Comparison of endocrine function in normal and genetically athymic mice. Comparative biochemistry and physiology. A, Comparative physiology. 1974;47: 93-100.

[32]. Zipper J., Tatum H.J., Medel M., Pastene L. and Rivera M. Presented at the 15th Nobel Symposium on Control of Human Fertility. 1970;May 27-29.

[33]. Dym M, Clermont Y. Role of spermatogonia in the repair of the seminiferous epithelium following $\mathrm{X}$-irradiation of the rat testis. Am. J. Anat. 1970;128:265-282.

[34]. Kincl F.A., Rudel H.W. Possible Mechanism of the Anti-Fertility Effect of Copper Current Problems in Fertility 1971;pp 187-190.

[35]. Potapov, A., Merrill, E., Pybus, M., \& Lewis, M. A.. Chronic Wasting Disease: Transmission Mechanisms and the Possibility of Harvest Management. PloS one, 2016;11(3).

[36]. Guaragna, Regina \& B. S. Rosa, Neila \& G. S. Moraes, Galba \& L. S. Perry, Marcos \& A. Bernard, Elena. Effect of protein malnutrition on glycoprotein synthesis by testes of 20 day old rats. International journal of andrology. 1987;9: 467-76.

[37]. Smith NM, Byard RW, Bourne AJ Testicular regression syndrome-a pathological study of 77 cases. Histopathology 1991;19:269-272.

How to cite this article:

P.Murali, J. Radhika, HISTOMORPHOMETRIC CHANGES OF GONADS IN MALE GUINEA PIGS AFTER THYMECTOMY. Int J Anat Res 2019;7(4.3):7187-7192. DOI: 10.16965/ijar.2019.338 